\title{
THE REPRODUCTIVE HISTORIES OF MOTHERS OF PATIENTS SUFFERING FROM CONGENITAL DIPLEGIA
}

\author{
BY \\ T. T. S. INGRAM and ELSPETH M. RUSSELL \\ From the Department of Child Life and Health, Edinburgh, and \\ Scottish Council for Care of Spastics, Edinburgh
}

(RECEIVED FOR PUBLICATION JUNE 14, 1960)

The aetiology of congenital cerebral diplegia has been controversial since the earliest medical interest in the condition. Some authors have considered birth injury to be directly causal in the majority of patients (Little, 1862; McNutt, 1885; Gowers, 1888). Others have postulated the existence of some underlying intrinsic abnormality of maternal reproductive capacity causing both disorders of parturition and abnormalities of the foetus (Freud, 1897; Collier, $1899 ; 1923)$. Penrose (1938) suggested that diplegia with mental defect might be the result of a Mendelian recessive gene which could also be manifest as true microcephaly without diplegia.

The present study describes investigations into the reproductive histories of mothers in two series of diplegic patients, which aimed at discovering whether their reproductive capacity was impaired or not.

\section{Terminology and Classification of Patients}

By 'diplegia' is understood a more or less symmetrical paresis of cerebral origin, more severe in the lower limbs than the upper and dating from birth or shortly afterwards. The legs and pelvis are underdeveloped. Mental defect, epilepsy and strabismus are commonly found. The category excludes patients in whom involuntary movements or ataxia are marked clinical features. Diplegic patients may be further classified according to the state of muscle tone in the affected limbs, the extent of limb involvement and its severity (Balf and Ingram, 1955). Patients with diplegia of postnatal onset were excluded from the series.

\section{Selection of Patients and Methods of Study}

Two series of mothers were studied, the first (Series A) consisted of 78 mothers of 79 diplegic patients (there being one pair of affected identical twins). Three other patients were one of twins. These patients were born between 1938 and 1952 and were living in Edinburgh in 1952 to 1953 when a survey of cerebral palsy amongst children in the city was undertaken. Forty-nine of the patients were boys and 30 were girls. Their cerebral palsy was actively ascertained in a number of different ways and it is probable that this series of patients is representative of children suffering from congenital diplegia in the community (Ingram, 1955). Detailed family, birth, developmental and medical histories were taken from the mothers. Questions about the course of other pregnancies, the health of the patients' sibs, and the mothers' own health were asked specifically. Maternity hospital notes of the patients and their sibs were obtained, when available, to supplement information given by the mother. The sibs were inspected wherever possible and if there was any suspicion of congenital malformation or neurological abnormality they were examined if permission was given. Unfortunately the study of the mothers' reproductive histories was incomplete. The investigator neglected, for example, to obtain the date of the parents' marriage and full details of mothers' contraceptive habits or menstrual histories in many cases. Nevertheless, the results of the investigation suggested that the mothers of diplegic patients were relatively infertile, had many abnormal pregnancies, labours and deliveries and produced relatively few healthy offspring of average intelligence (Ingram, 1959).

In order to confirm these findings and to remedy deficiencies in the earlier investigation a further, larger series of 200 mothers with children suffering from congenital diplegia was studied (Series B). The patients were consecutive referrals from all parts of Scotland, suffering from congenital diplegia who had been sent to the Edinburgh Clinic of the Scottish Council for the Care of Spastics between 1945 and 1959. One hundred and seventeen were male, 83 were female and $20(10 \%)$ of the patients were one of twins. Their ages ranged from 13 months to 30 years at the time of the survey, but two-thirds were between 5 and 15 years of age. Many children were referred because they were felt to be suitable for Westerlea (a school for spastics 
catering for patients with relatively high intelligence); others because their parents were well-informed people anxious to bring their offspring for examination in Edinburgh. Thus the patients tended to be preselected by social class, intelligence and probably other characteristics. They did not form a representative group of diplegic children drawn from the community.

At the clinic, parents and patients were interviewed by a social worker, paediatrician, psychologist, and orthopaedic surgeon. Detailed accounts of family, birth, developmental and medical history were obtained and the patients examined. The records of the clinic were available to the investigator who supplemented them by reference to hospital notes describing the births and hospital admissions of patients and their sibs, by personal interviews with parents and relatives and by her own examination of the patients. In 150 instances patients and their parents were seen in their own homes. In the remainder, either information in the case notes was adequate or the patients had emigrated or lived in very remote parts of the country. In the latter group questionnaires were utilized. Since this study was predominantly concerned with maternal factors in the aetiology of diplegia other members of the families of patients were not examined.

\section{Results of the Investigations}

Social Class. The distribution of patients by social class of their fathers compared to that of all live births in Scottish Counties of Cities, 1951, is shown in Fig. 1 (Registrar General for Scotland, 1951). In series $A$ there was an excess of patients in social classes I, II, IV and V at the expense of social class III, compared to all live births, differences of distribution which are of statistical significance $(p<0.05)$. In series $B$ there was also an excess of patients in social classes I and II at the expense of III, but no excess in the combined classes IV and V. The difference between the series was probably largely the result of the parents of patients in social classes IV and V not taking their offspring to be examined so readily as those in classes I and II.

Birth Rank of Patients. The proportion of patients suffering from diplegia in each birth rank was compared to the expected proportion, taking into consideration family size. In series $A$, no statistically significant differences in the distribution of patients by birth rank were found. In series B, however, a significantly higher proportion of diplegic patients were first-born than would be expected ( $p<0.01)$. This may represent an actual increased liability for the first-born child to suffer

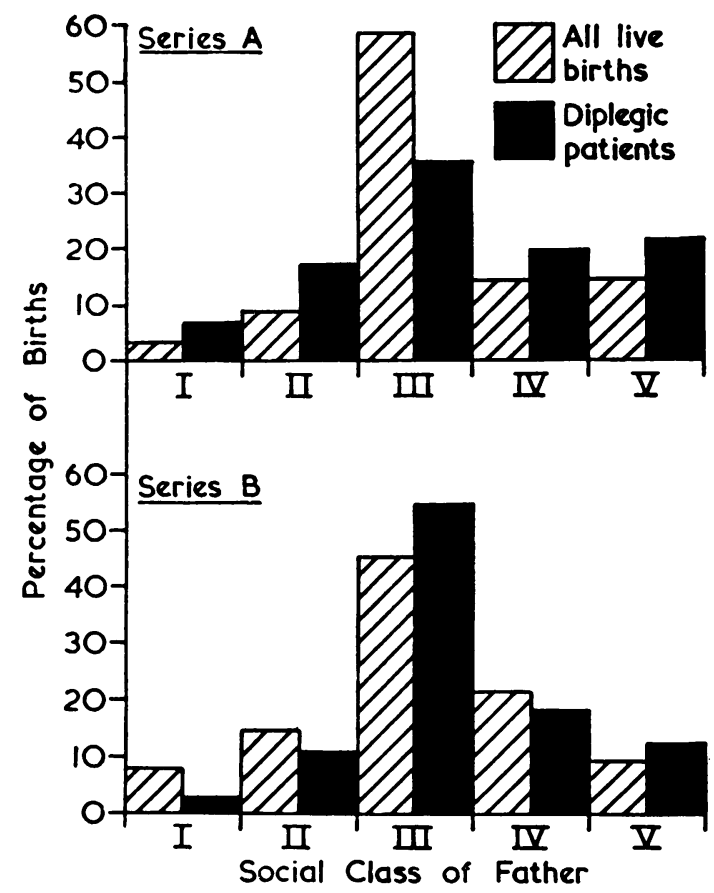

FIG. 1.-Comparison of percentage distribution of patients by social class. Patients in Series A are compared with live births in Counties of Cities in Scotland, 1951. Patients in Series B are compared with all live births in Scotland, 1951.

from diplegia or it may merely reflect a tendency for parents to refer their first-born diplegic children more readily than those born later.

Maternal Age. The distribution of mothers in series B by age at marriage was compared to that for mothers in the general population of Scotland (Registrar General for Scotland, 1951). There is a tendency for the age at marriage to be greater in mothers of diplegic children, the maximum marriage rate occurring in the age group 25-29 years, whereas the rate in the general population is highest between the ages of 21 and 24 years. The older age of marriage of the mothers of diplegic children may be partly a reflection of the relatively high proportion of fathers in social classes I and II, in which marriage tends to occur later than in the other social classes.

Maternal age at the time of the birth of the patients in both series was studied and compared to the age of mothers of all live births in Scotland in 1951 (Fig. 2). In both series there are more mothers over 30 years of age than under, whereas the majority of mothers of live births in 1951 were under 30 years. In both series, the peak distribution of mothers by age occurs between 30 and 35 years, 


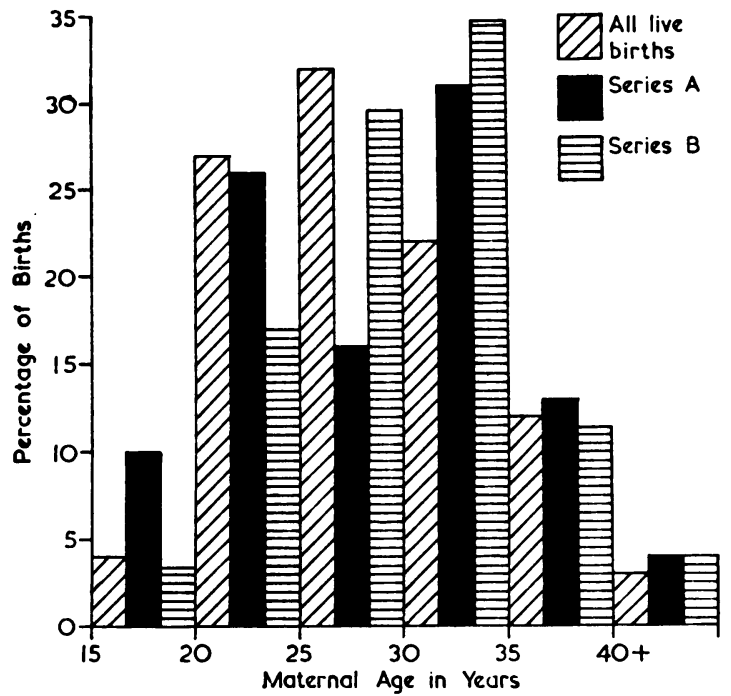

Fig. 2.-Distribution, by maternal age at delivery, of 77 patients in Series A, and 198 in Series B, compared to that for all live births in Scotland, 1951.

whereas the peak distribution of mothers in the Scottish population is in the age range 25-30 years. There is one striking difference between the two series. Whereas there is a significant excess of mothers under the age of 20 years compared to mothers in the general population in series $\mathrm{A}$, this is not found in series $\mathbf{B}$. This difference is probably related to the fact that a higher proportion of mothers in series A were in social classes IV and V (in which maternal age tends to be low) than mothers in series B or mothers in the general population.

Maternal Health and Menstrual History. The methods of the investigation could not give a com-

TABLE 1

PHYSICAL DISORDERS AMONGST 78 MOTHERS OF DIPLEGIC PATIENTS IN SERIES A AND 170 MOTHERS IN SERIES B

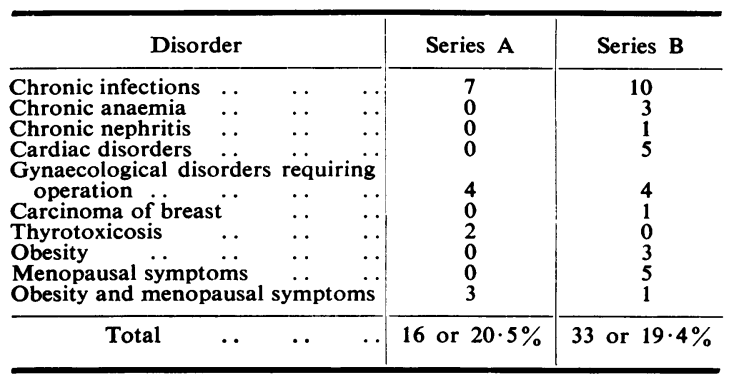

plete picture of the health of mothers of the patients in either series though some information was obtained (Table 1). In series A $20 \%$ of the mothers and in series B $19 \%$ were considered to be unhealthy. In series B, 161 mothers were asked about their menstrual history. The average age of the menarche was 13.5 years, a figure very similar to that of Edinburgh women (13.35 years) studied by Provis and Ellis (1955). Menstrual irregularities were reported by only nine of the 161 mothers, findings which do not suggest that menstrual abnormalities occur frequently.

Birth Rates of Mothers of Diplegic Patients. Average birth rates were calculated for married women in both series and were found to be 129.5 per 1,000 in series A and $128 \cdot 1$ per 1,000 in series B. The figures were compared to those given by the Registrar General in 1951 for married women of comparable age in comparable communities (Table 2). The average birth rate given for married women in the general population of Scotland (1951) was $132 \cdot 2$ per 1,000 , and for married women in Scottish Counties of Cities (1951) was $126 \cdot 8$ per 1,000 . Married women in the general population, however, include a significant proportion who are childless, probably about $15 \%$ in Scotland (Registrar General for Scotland, 1951). If the proportion were excluded, the rates would be $155 \cdot 3$ and $149 \cdot 4$ per 1,000 respectively, indicating that mothers of diplegic children are relatively infertile compared to married women in the general population who have borne children.

A comparison was also made between the average numbers of live and stillbirths to mothers of diplegic patients at the time of the surveys and the average number of deliveries to married women having live and stillbirths in 1951. At the time of the surveys the mothers in series A and B had an average age of over 36 years and the majority could be considered to have completed their families. In contrast, the mothers in the general population had an average age of between 25 and 30 years in 1951, yet the average numbers of live and stillbirths of mothers of diplegic patients were only slightly higher (Table 2).

The smaller number of live and stillbirths was due only in part to deliberate restriction of family size following the birth of the diplegic child, for the average number of preceding deliveries was also smaller than the average number that preceded live and stillbirths in Scotland in 1951.

The Spacing of Pregnancies. The smaller number of live and stillbirths before the delivery of the 
diplegic child was not due to any longer delay in conceiving after marriage in series B. Mothers in this group gave birth to their first live or stillbirth 26 months after marriage, on average, compared to 29 months for all married mothers in Scotland giving birth in 1951. In series $\mathrm{B}$, the proportion of first births taking place within the first year of marriage $(48 \cdot 5 \%)$ was a little higher than the proportion $(40 \%)$ to married mothers in the general population in 1951 .

The spacing of pregnancies, irrespective of their outcome, was studied. The intervals between pregnancies were measured from the time of delivery or abortion. The average time elapsing between pregnancies was found to be greater than that which elapsed between the pregnancies of mothers of children suffering from other types of cerebral palsy (Table 3). There was a tendency in both series for pregnancies following the birth of the diplegic patient to be rather more widely spaced than those which preceded this birth. This difference in timing may be partly the result of increase in maternal age and decrease in fertility and partly due to contraception following the birth of an abnormal child. The most striking finding was that the lapse of time between the birth of the patient and the immediately preceding and subsequent pregnancies was very great when compared to the period between more remote previous and subsequent pregnancies. The mothers of patients with congenital and acquired hemiplegia showed the same tendency for contiguous pregnancies to be more widely spaced than remote pregnancies, but the differences were much less marked than with mothers of diplegic children (Table 3).

When the timing of abortions alone was considered an interesting distribution was found. More than half the abortions in both series took place immediately before or immediately after the pregnancy resulting in the birth of the diplegic child. This distribution is significantly different statistically from that expected.

Contraception. In series B, 148 married mothers who were living with their husbands were asked about their contraceptive practices. Only $6 \cdot 1 \%$ practised contraception in order to influence the spacing of their pregnancies, both before as well as after the birth of the diplegic child. Contraception was employed by $15.5 \%$ of parents only subsequent to the birth of the affected child. From these figures it is evident that contraception can only be incriminated in a minority of cases as a cause of the limited reproductive capacity of mothers of diplegic children.
TABLE 2

COMPARISON OF AGES, AVERAGE NUMBERS OF OFFSPRING AND BIRTH RATES OF DIPLEGIC PATIENTS AND MOTHERS IN THE GENERAL POPULATION OF SCOTLAND HAVING LIVE OR STILLBIRTHS IN 1951 (REGISTRAR GENERAL FOR SCOTLAND)

\begin{tabular}{|c|c|c|c|c|}
\hline & Series A & Series B & $\begin{array}{c}\text { Scotland, } \\
1951\end{array}$ & $\begin{array}{c}\text { Scottish } \\
\text { Counties } \\
\text { of Cities } \\
1951\end{array}$ \\
\hline $\begin{array}{c}\text { Average age (in yrs) } \\
\text { of mothers at time } \\
\text { of study } \ldots\end{array}$ & 36 & 40 & $25-30$ & $25-30$ \\
\hline $\begin{array}{l}\text { Average number of } \\
\text { live and stillbirths } \\
\text { at time of study... }\end{array}$ & $2 \cdot 6$ & $2 \cdot 8$ & $2 \cdot 5$ & - \\
\hline $\begin{array}{l}\text { Average age (in yrs) } \\
\text { at birth of patients } \\
\text { or live and still- } \\
\text { births in } 1951 \quad .\end{array}$ & 29 & 29 & $25-30$ & $25-30$ \\
\hline $\begin{array}{l}\text { Average number of } \\
\text { surviving and still- } \\
\text { born offspring } \\
\text { before birth of } \\
\text { patients or chil- } \\
\text { dren born in } 1951\end{array}$ & $1 \cdot 0$ & $1 \cdot 2$ & $1 \cdot 5$ & - \\
\hline $\begin{array}{c}\text { Birth rate per } 1,000 \\
\text { married women } \\
\text { aged between } 16 \\
\text { and } 44 \text { years }\end{array}$ & $129 \cdot 5$ & $128 \cdot 1$ & $132 \cdot 2$ & $126 \cdot 8$ \\
\hline
\end{tabular}

TABLE 3

AVERAGE NUMBER OF MONTHS ELAPSING BETWEEN TERMINATION OF PREGNANCIES (INCLUDING ABORTIONS) BEFORE AND AFTER BIRTH OF DIPLEGIC AND HEMIPLEGIC PATIENTS

\begin{tabular}{|c|c|c|c|c|}
\hline & Series A & Series B & $\begin{array}{c}\text { Acquired } \\
\text { Hemiplegia }\end{array}$ & $\begin{array}{l}\text { Congenital } \\
\text { Hemiplegia }\end{array}$ \\
\hline $\begin{array}{l}\text { Number of mothers } \\
\text { with pregnancies } \\
\text { other than that } \\
\text { resulting in birth } \\
\text { of patient }\end{array}$ & 62 & 157 & 50 & 50 \\
\hline $\begin{array}{l}\text { Number of pregnan- } \\
\text { cies before birth of } \\
\text { patient }\end{array}$ & 71 & 243 & 84 & 54 \\
\hline $\begin{array}{l}\text { Number of pregnan- } \\
\text { cies after birth of } \\
\text { patient } \quad . .\end{array}$ & 59 & 181 & 66 & 51 \\
\hline $\begin{array}{c}\text { Average period (in } \\
\text { mths) elapsing be- } \\
\text { tween remote preg- } \\
\text { nancies before } \\
\text { birth of patient } . .\end{array}$ & 28 & $27 \cdot 5$ & 27 & 24 \\
\hline $\begin{array}{c}\text { Average period (in } \\
\text { mths) elapsing be- } \\
\text { tween immediate } \\
\text { previous pregnan- } \\
\text { cy and birth of } \\
\text { patient .. }\end{array}$ & 34 & 41 & 43 & 32 \\
\hline $\begin{array}{cr}\begin{array}{c}\text { Average } \\
\text { elapsing }\end{array} & \begin{array}{r}\text { period } \\
\text { between }\end{array} \\
\text { birth of patient } \\
\text { and immediately } \\
\text { subsequent } \\
\text { nancy }\end{array}$ & 34 & 40 & 40 & 37 \\
\hline $\begin{array}{l}\text { Average period elap- } \\
\text { sing between re- } \\
\text { mote subsequent } \\
\text { pregnancies } . .\end{array}$ & 20 & $31 \cdot 5$ & 31 & 27 \\
\hline
\end{tabular}




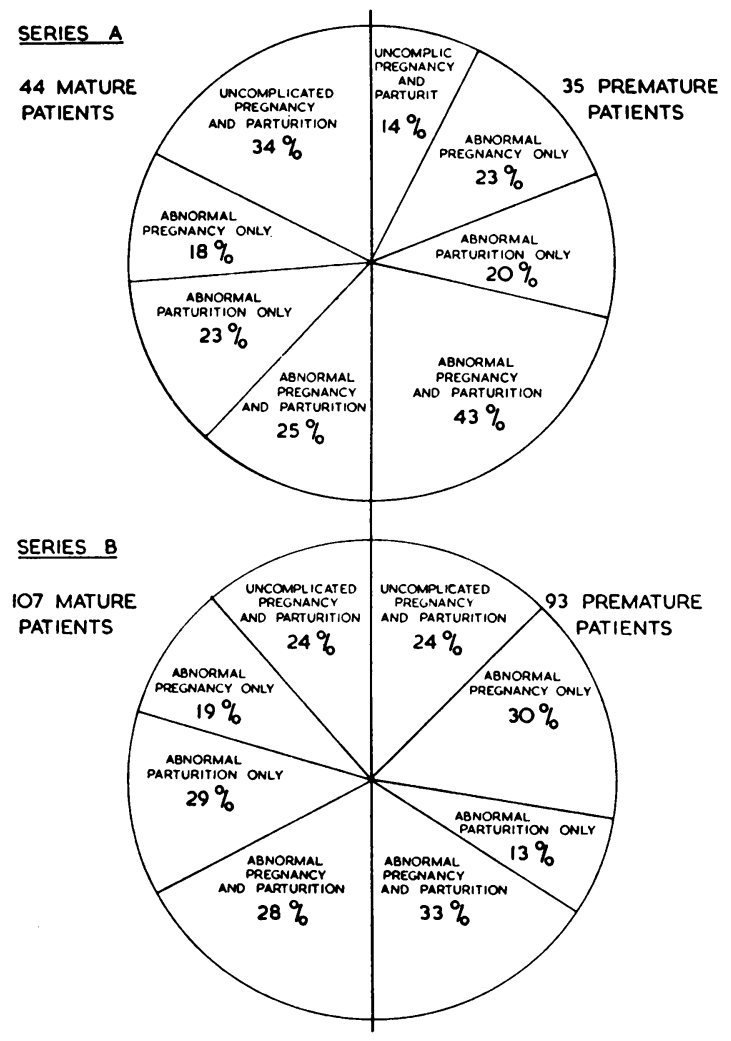

Fig. 3.-Abnormalities of the pregnancies, labours and deliveries resulting in the birth of diplegic patients.

Pregnancies Resulting in the Birth of Diplegic Patients. The pregnancies and deliveries resulting in the birth of the diplegic child were more often complicated than the mothers' other pregnancies. Nevertheless a considerable proportion of diplegic patients were born after normal pregnancies. Taking both series together, between one quarter and one third of pregnancies resulting in diplegic patients showed no abnormality apart from premature birth.

Pregnancy, labour and delivery were considered separately and the proportion of abnormalities in each was noted (Fig. 3).

The Other Pregnancies of Mothers of Diplegic Patients. Mothers in both series had a high proportion of disordered pregnancies, labours and deliveries not only with the patient but also with prior and subsequent conceptions. Only $53 \%$ of the multiparous mothers in series $\mathrm{A}$ and $50 \%$ in series B had other pregnancies, labours and deliveries which were all normal. The commonest abnormalities of pregnancy and parturition in both series

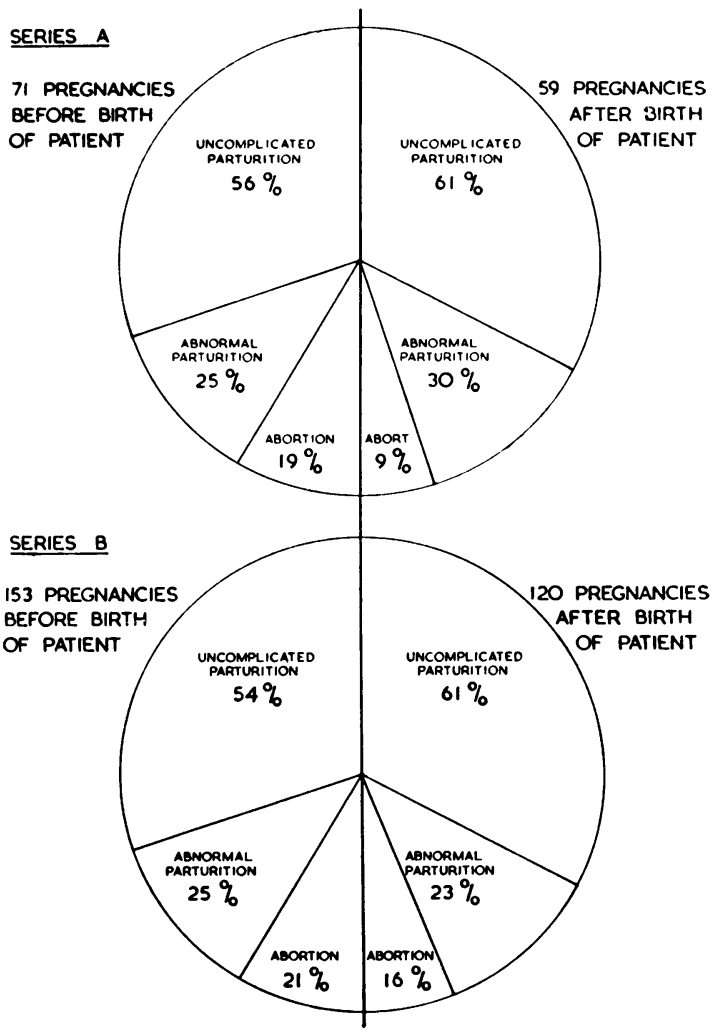

FIG. 4.-The proportion of abnormal pregnancies before and after the births of diplegic patients.

were threatened abortion, pre-eclampsia, antepartum haemorrhage, prolonged labour, forceps delivery, breech extraction and premature birth, several of which occurred in association in many cases. No particular abnormality occurred strikingly often, relative to the incidence of the other disorders, but approximately $12 \%$ of all pregnancies in both series (other than those ending in abortion) resulted in the birth of premature infants. Pregnancies before and after the birth of the diplegic patients were separately analysed for abnormalities but no statistically significant differences were found. In both series between one quarter and one third of all pregnancies, labours and deliveries (other than those which terminated in abortion or in the birth of diplegic patients) were abnormal. When abortions are included, between one third and one half of other pregnancies were complicated (Fig. 4).

The Fate of all Conceptions of Mothers of Diplegic Patients. The fate of all the known conceptions of mothers in both series was studied. It was found 
that a high proportion of them failed to result in the birth of healthy offspring, of average intelligence who survived the first year of life (Fig. 5). In both series, about $10 \%$ of conceptions ended in abortion. The combined stillbirth and infant mortality rate in series A was similar to that for the population in Scotland in 1951, but the combined rate in series B was almost twice as great in spite of the fact that so many mothers were in the social classes I and II (Table 4).

From Fig. 5 it will be seen that in both series about half the offspring who survived infancy were abnormal, the majority comprising the diplegic patients. A considerable proportion of live born sibs suffered from mental and neurological abnormalities and developmental malformations, although full details about them were impossible to obtain.
The available information about both live and dead sibs is summarized in Table 5 . In series A two sibs suffered from cerebral palsy, neither of them being diplegic; in series $B$ one sib suffered from diplegia and two from other kinds of cerebral palsy.

It was interesting to find that there was no significant difference in the proportion of abnormal pregnancies, labours and deliveries resulting in the birth of normal sibs and those resulting in the birth of abnormal sibs including those who died in infancy.

When the conceptions which ended in abortion, stillbirth, infant death, and the birth of patients and their abnormal sibs are subtracted from the total conceptions, it is found that, in neither series did more than half result in the birth of healthy children of average intelligence. These figures represent a high foetal and infant casualty rate.

TABLE 4
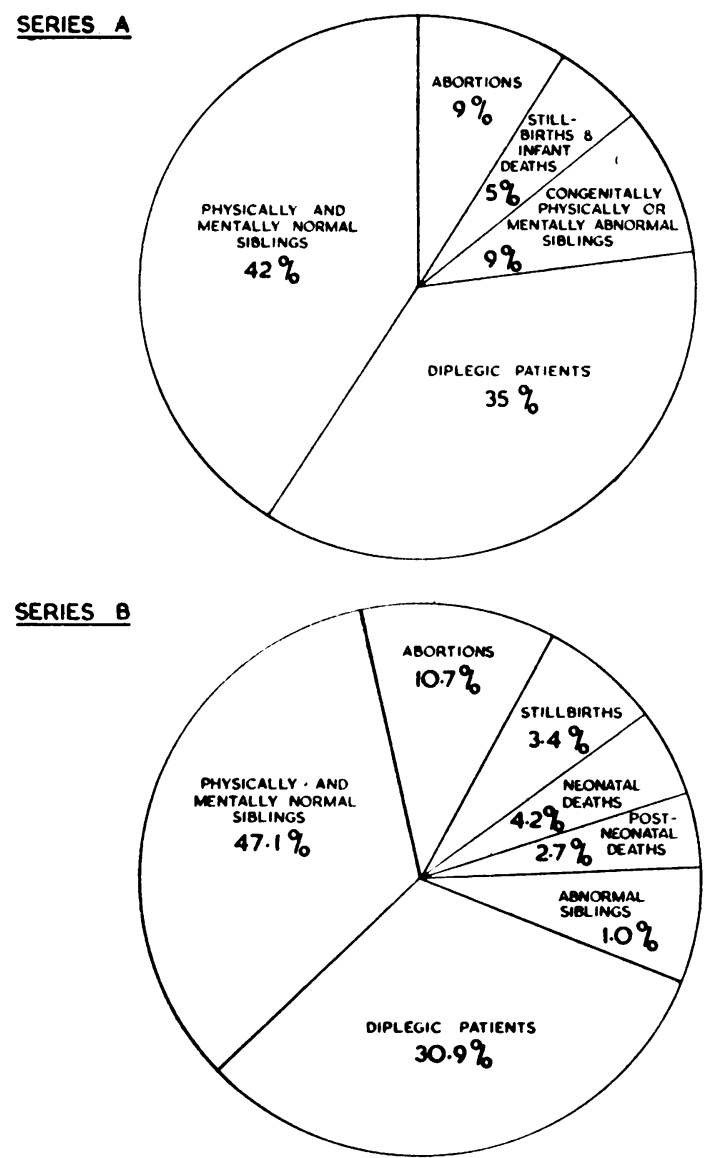

FIG. 5.-The results of 214 conceptions to 75 mothers of children suffering from diplegia in Series $A$ and 646 conceptions to 200 mothers in Series B.
COMBINED STILLBIRTH, NEONATAL AND POST-NEONATAL DEATH RATES, BY SOCIAL CLASS OF OFFSPRING

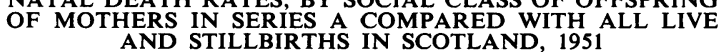

\begin{tabular}{c|c|c|c}
\hline Death Rates & \multicolumn{2}{|c|}{ Social Class } \\
\cline { 2 - 4 } & 1 and II & III & IV and V \\
\hline $\begin{array}{c}\text { Series A. } \begin{array}{c}\text { Combined rate per } \\
1,000 \text { live and stillbirths }\end{array} \\
\begin{array}{r}\text { Combined rate per 1,000 live and } \\
\text { stillbirths in Scotland, 1951 .. }\end{array}\end{array}$ & $84 \cdot 1$ & $124 \cdot 5$ & $129 \cdot 4$ \\
\hline
\end{tabular}

TABLE 5

CONGENITAL ABNORMALITIES OF LIVING SIBLINGS OF DIPLEGIC PATIENTS, AND CAUSES OF DEATH OF SIBLINGS DYING IN THE FIRST YEAR OF LIFE

\begin{tabular}{|c|c|c|c|c|c|}
\hline \multicolumn{4}{|c|}{ Condition } & \multirow{2}{*}{$\begin{array}{c}\text { Series A } \\
2^{*} \\
2 \\
11 \\
0 \\
2\end{array}$} & \multirow{2}{*}{ 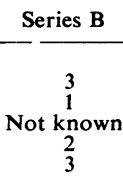 } \\
\hline $\begin{array}{l}\text { Surviving siblings } \\
\text { Cerebral palsy ... } \\
\text { Epilepsy } \\
\text { Mental retardation } \\
\text { Mongolism } \\
\text { Other malformations }\end{array}$ & $\begin{array}{l}\cdots \\
\cdots \\
\cdots \\
\cdots\end{array}$ & $\begin{array}{l}\cdots \\
\cdots \\
\cdots \\
\cdots\end{array}$ & \begin{tabular}{l|}
$\cdots$ \\
$\cdots$ \\
$\cdots$ \\
$\cdots$
\end{tabular} & & \\
\hline \multicolumn{4}{|c|}{$\begin{array}{l}\text { Siblings who died neonatally } \\
\text { Spina bifida } \\
\text { Multiple congenital deformities } \\
\text { Convulsions and cerebral haemorrhage }\end{array}$} & $\begin{array}{ll}1 & \\
2 & 1 \\
2 & \\
0 & \\
0 & \end{array}$ & $\begin{array}{r}0 \\
0 \\
1 \\
15 \\
2 \\
8\end{array}$ \\
\hline Total .. & $\cdots$ & $\cdots$ & $\cdots$ & 6 & 26 \\
\hline $\begin{array}{l}\text { Siblings who died post-ne } \\
\text { Febrile convulsions } \\
\text { Meningitis } \quad . \\
\text { Encephalitis } \quad . \\
\text { Spina bifida . . } \\
\text { Congenital heart disea } \\
\text { Other and unknown c }\end{array}$ & $\begin{array}{l}\text { eonatal } \\
\ldots \\
\cdots \\
\cdots \\
\ldots \\
\text { ase } \\
\text { auses }\end{array}$ & $\begin{array}{l}y \\
\cdots \\
\cdots \\
\cdots \\
\cdots \\
\cdots\end{array}$ & \begin{tabular}{l|}
$\cdots$ \\
$\cdots$ \\
$\cdots$ \\
$\cdots$ \\
$\cdots$
\end{tabular} & $\begin{array}{l}3 \\
0 \\
1 \\
0 \\
0 \\
0\end{array}$ & $\begin{array}{l}3 \\
2 \\
1 \\
2 \\
1 \\
3\end{array}$ \\
\hline Total ... & $\ldots$ & $\ldots$ & $\ldots$ & 4 & 17 \\
\hline \multicolumn{2}{|l|}{ Total live born siblings } & & $\cdots$ & 193 & 358 \\
\hline
\end{tabular}

* Excluding identical diplegic twins. 


\section{Discussion}

Underlying abnormalities of maternal reproductive capacity which might be responsible for abnormalities of the foetus and abnormalities of parturition were postulated as the cause of diplegia in a proportion of cases by Freud (1897). Arguments based on the clinical and pathological findings to support this theory were offered vehemently by Collier $(1899,1923)$. He was impressed by the remarkable symmetry of the neurological abnormalities, the pathological appearances, and by the frequency with which associated malformations were observed. He felt that 'diplegia' was more likely to be the result of either intrinsic failures of neuronal development or of processes of neuronal degeneration, than to be directly attributable to birth injury. A somewhat similar argument in favour of diplegia being due to cerebral maldevelopment more often than to birth injury was presented by Yannet (1944). Stewart, however, emphasized the diversity of pathological appearances and thought that different aetiological agents were probably important in different patients though he thought that Collier's explanations were valid for a considerable proportion of cases (Stewart, 1942). Recent studies have attempted to define two groups of diplegic patients. First, those with relatively uncomplicated paraplegia who tend to be born prematurely after pregnancies, labours and deliveries which were not disordered; second, patients with complicated diplegia (triplegia or tetraplegia), often with mental retardation and epilepsy who were more often born at term after disordered parturition (Childs and Evans, 1954; Polani, 1958, 1959; Russell, 1960). There appear to have been remarkably few attempts to discover if the mothers of diplegic patients do, in fact, show evidence of underlying abnormalities of reproductive capacity.

The findings in the present investigations support the thesis that mothers of diplegic patients may have underlying abnormalities of reproductive capacity. These are manifest in the paucity of their conceptions, the frequency with which there were disorders of pregnancy, labour and delivery and their tendency to produce poor quality or malformed offspring, many of whom died in infancy. The abnormalities of the offspring could not be related consistently to abnormalities of parturition for their pregnancies, labours and deliveries were no more often disordered than those of healthy sibs.

There is some evidence to suggest that the effects of possible underlying abnormalities of reproductive capacity are greater at the time of gestation of the diplegic patients than at other times. The periods of infertility immediately before and immediately after the birth of the diplegic child are greater than the periods which elapse between more remote previous and subsequent pregnancies. More of the contiguous conceptions end in abortion or are otherwise disordered than are pregnancies, labours and deliveries which are more remote.

The finding of a period of particularly impaired reproductive capacity at about the time of birth of the diplegic child allows a different interpretation than the usual one of high incidence of abnormal pregnancy and parturition resulting in the birth of diplegic patients. The temporary increase in the severity of the effects of the underlying abnormalities of reproductive capacity might be expected to result in a higher incidence of disordered parturition and also in a higher incidence of foetal abnormality. Therefore foetal abnormality (in this case, diplegia) and abnormal parturition would be likely to occur more frequently than in periods of greater fertility. On the other hand they would not be expected to be present together in all cases, for in some only parturition would be affected and in others the foetus would be abnormal but parturition uncomplicated. It seems easier to explain the quarter to one third of normal pregnancies, labours and deliveries resulting in the birth of diplegic patients in this way than to assume that severe birth injury occurred in them all, without clinical abnormality of parturition being apparent.

It is possible, however, to suggest a number of other interpretations of the findings. The underlying defect of reproductive capacity may not affect the foetus by causing diplegia directly. The effect may be to predispose the child to suffer arrest of cerebral development or neuronal fall out, should the natal or postnatal environment be the least unfavourable. Thus minor degrees of natal or postnatal hypoxia, which would not be damaging to normal healthy infants might cause marked brain damage in those who had been predisposed. It is possible to postulate that there are cases in which the foetus is only mildly predisposed to suffer from arrest of cerebral development or neuronal degeneration. In these, gross hypoxia or trauma during parturition would be required to cause brain damage. In more severely predisposed patients, however, relatively slight hypoxia or trauma during birth might be sufficient to cause cerebral abnormalities. Unfortunately it is possible only to speculate about the nature of these predisposing factors.

The nature and mechanisms of action of abnormalities of maternal reproductive capacity are also obscure. High maternal age is certainly important in causing diminished fertility, an increased prevalence of abnormalities of pregnancy and par- 
turition and an increased incidence of foetal malformation (Murphy, 1940). A number of chronic illnesses, notably diabetes, thyrotoxicosis and gynaecological disorders, diminish fertility and have been thought to be associated with an increased incidence of foetal malformation and abnormalities of parturition. One-fifth of the mothers in the Edinburgh series were found to be suffering from chronic diseases, a high proportion of which affected the reproductive system but the way in which these disorders may have acted to cause foetal abnormality and disorders of the reproductive mechanism is largely unknown. Similarly it is impossible to assess the importance of abnormalities of male reproductive function or of mutating or recessive genes in the aetiology of diplegia on the basis of the present data. It may well be that the rapidly developing methods of genetic research may make fundamental contributions in this field.

\section{Summary}

The reproductive histories of 278 mothers of diplegic patients in two series were examined. Mothers of diplegic patients were older when they married than were women in the general population of Scotland. More were over 30 years of age when they gave birth to diplegic children than expected.

Mothers of diplegic children had fewer conceptions than married child-bearing women in the population of Scotland and their pregnancies were more widely spaced. A high proportion of their pregnancies aborted or were otherwise abnormal. Many of their offspring were stillborn, died in infancy or showed neurological or other defects if they survived. Less than half the conceptions resulted in the birth of healthy offspring who survived the first year of life.

There tended to be periods of relatively decreased fertility immediately before and after the birth of patients. Pregnancies contiguous to those resulting in the birth of diplegic children were more often abnormal than those which were more remote.

The findings are thought to provide some evidence in support of the theory that underlying abnormalities of the reproductive process in mothers of diplegic children, may be responsible for both disorders of pregnancy, labour and delivery and for the production of abnormal offspring.

These investigations were made possible by the Scottish Council for the Care of Spastics who provided facilities for research including financial support. Dr. J. A. Naughton and Mr. G. A. Pollock kindly granted free access to the Council's records. We are grateful for the support and helpful advice of Professor R. W. B. Ellis during both the investigations and in the preparation of this paper. Mr. Cyril Shepley kindly made our diagrams. We have received much secretarial help from Miss B. Sinclair of the Scottish Council for the Care of Spastics.

These investigations were carried out during the tenure, by Dr. Russell, of a graduate research fellowship from the University of Edinburgh, in 1959-60 and the tenure by Dr. Ingram of a George Guthrie Research Fellowship in the University of Edinburgh in 1952-1953.

\section{REFERENCES}

Balf, C. L. and Ingram, T. T. S. (1955). Problems in the classification of cerebral palsy in childhood. Brit. med. J., 2, 163.

Childs, B. and Evans, P. R. (1954). Birth weights of children with cerebrai palsy. Lancet, 1, 642 .

Collier, J. S. (1899). Cerebral diplegia. Brain 22, 373.

- (1923). The pathogenesis of cerebral diplegia. Ibid, $2,1129$.

Freud, S. (1897). Die infantile Cerebrallähmung. In Specielle Pathologic und Therapie, ed. $H$. Nothnagel, Band 9, Theil 2, Abt. 2. p. 6, IIa. Geschichte und Literatur der hemiplegischen infantilen Cerebrallähmung. Hölder, Vienna.

Gowers, W. R. (1888). Clinical lecture on birth palsies. Lancet, 1. 709 .

Ingram, T. T. S. (1955). A study of cerebral palsy in the childhood population of Edinburgh. Arch. Dis. Childh., 30, 85.

(1959). The fertility of mothers of diplegic children and the fate of their conceptions. Paper to the British Paediatric Association, 1959. Ibid., 34, 357.

Little, W. J. (1862). On the influence of abnormal parturition, difficult labours, premature birth, and asphyxia neonatorum, on the mental and physical condition of the child, especially in relation to deformities. Trans. obstet. Soc Lond, 3,293

McNutt, S. J. (1885). Double infantile spastic hemiplegia, with the report of a case. Amer. J. med. Sci., 89, 58.

Murphy, D. P. (1940). Congenital Malformations; A Study of Parental Characteristics with Special Reference to the Reproductive Process. University of Pennsylvania Press, Philadelphia; Oxford University Press, London.

Penrose, L. S. (1938). A clinical and genetic study of 1,280 cases of mental defect. Spec. Rep. Ser. med. Res. Coun. (Lond.), No. 229, H.M.S.O

Polani, P. E. (1958). Prematurity and 'cerebral palsy'. Brit. med.J., 2, 1497 .

(1959). Effects of abnormal brain development on function. Cerebral Palsy Bull., No. 7, p. 27.

Provis, H. S. and Ellis, R. W. B. (1955). An anthropometric study of Edinburgh schoolchildren. Part I. Arch. Dis. Childh., of 328 .

Registrar General for Scotland (1951). Annual Reports.

Russell, E. M. (1960). Correlation between birth weight and clinical findings in diplegia. Arch. Dis. Childh., 35, 548.

Stewart, R. M. (1942). Observations on the pathology of cerebral diplegia. Proc. roy. Soc. Med., 36, 25.

Yannet, H. (1944). The etiology of congenital cerebral palsy. A statistical and clinical study. J. Pediat., 24, 38. 